\title{
Glycogen Synthase Kinase-3: a Putative Molecular Target for Lithium Mimetic Drugs
}

\author{
Todd D Gould*,I and Husseini K Manji' \\ 'Laboratory of Molecular Pathophysiology, National Institute of Mental Health, Bethesda, MD, USA
}

\begin{abstract}
Despite many decades of clinical use, the therapeutic target of lithium remains uncertain. It is recognized that therapeutic concentrations of lithium, through competition with the similarly sized magnesium cation, inhibit the activity of select enzymes. Among these is glycogen synthase kinase-3 (GSK-3). Recent preclinical evidence, including biochemical, pharmacological, genetic, and rodent behavioral models, supports the hypothesis that inhibition of GSK-3 may represent a target for lithium's mood-stabilizing properties. Specifically, it has been demonstrated that lithium administration regulates multiple GSK-3 targets in vivo and that multiple additional classes of mood-stabilizing and antidepressant drugs regulate GSK-3 signaling. Pharmacological or genetic inhibition of GSK-3 results in mood stabilizer-like behavior in rodent models, and genetic association studies implicate GSK-3 as a possible modulator of particular aspects of bipolar disorder including response to lithium. Furthermore, numerous recent studies have provided a more complete understanding of GSK-3's role in diverse neurological processes strengthening the hypothesis that GSK-3 may represent a therapeutically relevant target of lithium. For example, GSK-3 is a primary regulator of neuronal survival, and cellular responses to glucocorticoids and estrogen may involve GSK3-regulated pathways. While the preclinical evidence discussed in this review is encouraging, ultimate validation of GSK-3 as a therapeutically relevant target will require clinical trials of selective novel inhibitors. In this regard, as is discussed, there is a major effort underway to develop novel, specific, GSK-3 inhibitors.

Neuropsychopharmacology (2005) 30, 1223-1237, advance online publication, 13 April 2005; doi:I0.1038/sj.npp. I 30073 I
\end{abstract}

Keywords: manic-depressive illness; psychopharmacology; mania; depression; mood stabilizer; antidepressant

\section{LITHIUM: PAST, PRESENT, AND FUTURE}

Mood disorders such as bipolar disorder and unipolar depression are pervasive diseases typified by episodes of alterations in mood. Depressive episodes are characterized by a depressed mood, cognitive changes, psychomotor changes, and a host of neurovegetative symptoms. In bipolar disorder, while there exist diverse presentations, patients typically alternate between (albeit not in a $1: 1$ manner) episodes of depression (mostly indistinguishable from unipolar depression) and episodes of mania, which is characterized by a hyperaroused state (either euphoric or dysphoric), increases in motor activity, racing thoughts, impaired judgment, decreased amount of sleep, and an apparent decreased need for sleep. Lithium has utility in the treatment of both bipolar disorder and unipolar depression.

While reported first in the scientific literature as a treatment for bipolar disorder over 50 years ago and in

\footnotetext{
*Correspondence: Dr TD Gould, Laboratory of Molecular Pathophysiology, NIMH, NIH, 9000 Rockville Pike, Bldg. 35, Room IC-9I2, Bethesda, MD 20892-37| I, USA, Tel: + I 30 I 45 I 8435, Fax: + I 30 I 4800 I23, E-mail: gouldt@mail.nih.gov

Received 24 November 2004; revised 23 February 2005; accepted 24 February 2005

Online publication: 2 March 2005 at http://www.acnp.org/citations/ Npp030205040550/default.pdf
}

widespread clinical use worldwide for over 30 years, the explanation of why the simple monovalent cation lithium is useful for the treatment of mood disorders has thus far been elusive. In 1949, John Cade documented in the medical literature lithium salts as useful for the treatment of 'psychotic excitement' (Cade, 1949). This was followed by the work of Mogens Schou and others during the next two decades eventually solidifying lithium's position as a valuable treatment for bipolar disorder-for the acute and maintenance treatment of both mania and depression.

A number of double-blind studies have confirmed lithium's efficacy both in the acute treatment of mania, and for mania prophylaxis (Schou, 2001). While in practice lithium is often considered not to be effective as monotherapy for bipolar and unipolar depression, multiple studies have suggested that lithium may be useful for both the acute and prophylactic treatment of depression (see Souza and Goodwin (1991) and Bauer and Mitchner (2004) for meta-analysis and review). Unfortunately, many of the studies addressing monotherapy antidepressant effects suffered from some methodological shortcomings, in particular low sample sizes and the use of crossover study designs. Furthermore, lithium's antidepressant effects may be modest, resulting in statistical significance but insufficient clinical antidepressant effects in many cases. However, 
lithium has clear utility as an adjunct antidepressant in treatment refractory patients (Heninger et al, 1983). Overall, in placebo-controlled trials, lithium has been found useful as an adjunct medication for $45 \%$ of patients (Bauer et al, 2003). Lithium also has antisuicidal effects, the molecular antecedents of which are of considerable interest (Baldessarini et al, 2001; Goodwin et al, 2003; Muller-Oerlinghausen, 2001). In spite of lithium's past success and proven efficacy in treatment of mood disorders, it is not the perfect medication.

It is increasingly being recognized that mood disorders such as bipolar disorder and depression represent pervasive diseases characterized not merely by isolated episodes of depression and/or mania but also by increased morbidity and mortality. This arises not only from a rate of suicide approaching 15 percent, but the existence of significant medical comorbidities, often limited social and economic functioning, and poor interepisode recovery (see Evans and Charney (2003) and accompanying issue of Biological Psychiatry). The entire current pharmacopia useful for the treatment of mood disorders (including lithium, anticonvulsants, antipsychotics, and antidepressants) often do not bring about full remission, and if they do, do so after a minimum of many weeks, if not months of treatment. Additionally, currently available medications often lack the ability to completely prevent breakthrough episodes, and, generally, have undesirable side effects even in the best efficacy scenarios (eg sexual side effects with selective serotonin reuptake inhibitors). In a critique of the efficacy of current antidepressants, Walsh et al (2002) found that compounds successful in double-blind placebo control studies for the treatment of depression are efficacious only about $50 \%$ of the time, where as placebo groups generally see about a $30 \%$ response.

The recognition of the significant morbidity and mortality of patients with severe mood disorders, as well as the growing appreciation that a significant percentage of patients either do not respond fully to existing treatments or are intolerant of side effects has made the challenge of discovering novel therapeutic agents increasingly more prominent. Recent efforts to develop 'novel' medications for the treatment of mood disorders has relied primarily upon developing 'me too' drugs with a similar mechanism of actions to older medications (ie increasing synaptic monamine levels in depression) or testing drugs developed and approved for other indications (most generally antipsychotic and antiepileptic drugs) in hope that they may have efficacy in treating either bipolar mania or bipolar or unipolar depression.

However, it is without doubt that the development of medications, which share some targets of older antidepressants (SSRIs versus tricyclics), have altered the tolerability of drugs, and saved many lives. While development of a drug that mimics lithium's therapeutic target while not interacting with those targets that result in side-effects will similarly probably not cure bipolar disorder, it would likely revolutionize the tolerability, as SSRIs did for the treatment of depression in the 1980s. Further, understanding precisely how lithium acts, through clinical validation, will provide important clues regarding mood disorder pathophysiology. It is thus of critical importance to understand lithium's relevant therapeutic target.
At therapeutic concentrations, lithium inhibits a small number of enzymes through competition for a magnesiumbinding site (see Gould et al (2004c) for a review). While it is possible that this molecule has more than one initial direct target by which it exerts its mood-stabilizing effects, the most parsimonious explanation is that a single initial target is most relevant (akin to William of Ockham's razor-Pluralitas non est ponenda sine necessitate [Plurality should not be posited without necessity]). Thereafter, many downstream effects (eg, modulation of diverse signaling pathways) may be of relevance.

For more than a decade, the most widely accepted target for lithium has been inhibition of inositol monophosphatase (IMPase) and related enzymes. Theoretically, inhibition of IMPase in the brain would prevent recycling of inositol, thus depleting free inositol that is required for phosphoinositol-mediated intracellular signaling cascades. Indeed, extensive preclinical and some clinical studies have provided support for this hypothesis (see Atack (2000) for a review). In studies that are widely replicated, Allison and Stewart (1971) first reported that acute lithium administration to rats resulted in a decrease in brain inositiol. Moore et al (1999) found that 5-7 days of lithium administration to bipolar subjects resulted in a decrease of frontal lobe myoinositol levels. However, studies have not been able to determine if this effect of lithium has therapeutic relevance. This is in large part due to the lack of novel blood-brain barrier penetrant IMPase inhibitors. Previous industry efforts have resulted in numerous compounds; however, the best studied have failed due to being either extremely hydrophobic or hydrophilic (Atack, 1997). Thus, it has not been possible to directly test for true clinical evidence of therapeutic efficacy. Research efforts remain underway, and may still someday result in a clinically testable hypothesis.

In 1996, it was discovered that lithium inhibited the enzyme glycogen synthase kinase-3 (GSK-3) (Klein and Melton, 1996; Stambolic et al, 1996). These findings raised the possibility that GSK-3 inhibition might play a role in the treatment of bipolar disorder. However, the past 2 years have seen the emergence of exciting new biochemical, pharmacological, genetic, and rodent behavioral studies, all of which support the hypothesis that inhibition of GSK-3 represents a therapeutically relevant target for lithium's mood-stabilizing properties. In this perspectives paper, we review and synthesize this new data, and discuss the implications for the development of truly novel agents for the treatment of mood disorders.

\section{GSK-3: A PLURIPOTENT KINASE}

GSK-3 was characterized in 1980 as a protein that phosphorylated and deactivated glycogen synthase (Embi et $a l, 1980)$. It is a ubiquitous kinase, found in both neurons and glia, localized to the cytoplasm, nucleus, and mitochondria (see Jope and Johnson (2004) for a review). It is generally considered constitutively active and found as two isoforms, $\alpha$ and $\beta$ (51 and $47 \mathrm{kDa}$, respectively), that have $97 \%$ sequence homology in their catalytic domains, and generally (but not always) have similar biological effects. The constitutive activity arises from phosporylation of tyrosines 279 or 216 ( $\alpha$ and $\beta$, respectively), although there 
is some evidence of active regulation of this site in the brain (Bhat et al, 2000). Determining the kinases most responsible for phosphorylation of this serine is an active area of research.

The primary mechanism of regulation involves inhibitory phosphorylation of their N-terminal serines (21 and 9, respectively; see Frame and Cohen (2001) for a review). Phosphorylation of this site is very dynamic, as a number of pathways and kinases converge here; dephosphorylation is regulated by protein phosphatase 1 (Bennecib et al, 2000; Tanji et al, 2002; Zhang et al, 2003). GSK-3 activity is additionally regulated by binding proteins; for example, in the Wnt signaling pathway, GSK-3 phosphorylation of $\beta$ catenin is regulated by proteins adenomatous polyposis coli (APC), the scaffold protein Axin, and frequently rearranged in advanced T-cell lymphomas 1 (FRAT1). Most substrates recognized by GSK-3 have the amino-acid sequence -S-X-X$\mathrm{X}$-S-, where the C-terminal serine is phosphorylated and acts as a primer allowing GSK-3 to phosphorylate the Nterminal serine (Fiol et al, 1987). Phosphorylation of serine 9/21 appears to exert inhibitory effects on GSK-3 by interaction with its own binding site that interacts with the primed serine residues (Dajani et al, 2001; Frame et al, 2001).

One of the most notable qualities of GSK-3 is the vast number of signaling pathways that converge on this enzyme and, subsequently, an even greater number of biological targets (see Frame and Cohen (2001) and Grimes and Jope (2001b) for a review). However, the enzyme is perhaps best established in three pathways. As depicted in Figure 1, GSK3 functions as a regulator of the Wnt signaling pathway where activation determines cell fate in embryonic development. GSK-3 is normally active in the Wnt pathway, where its primary target is $\beta$-catenin. $\beta$-Catenin has multiple roles in the cell; it interacts with cadherin localized to the cell membrane, and acts as a transcription factor in

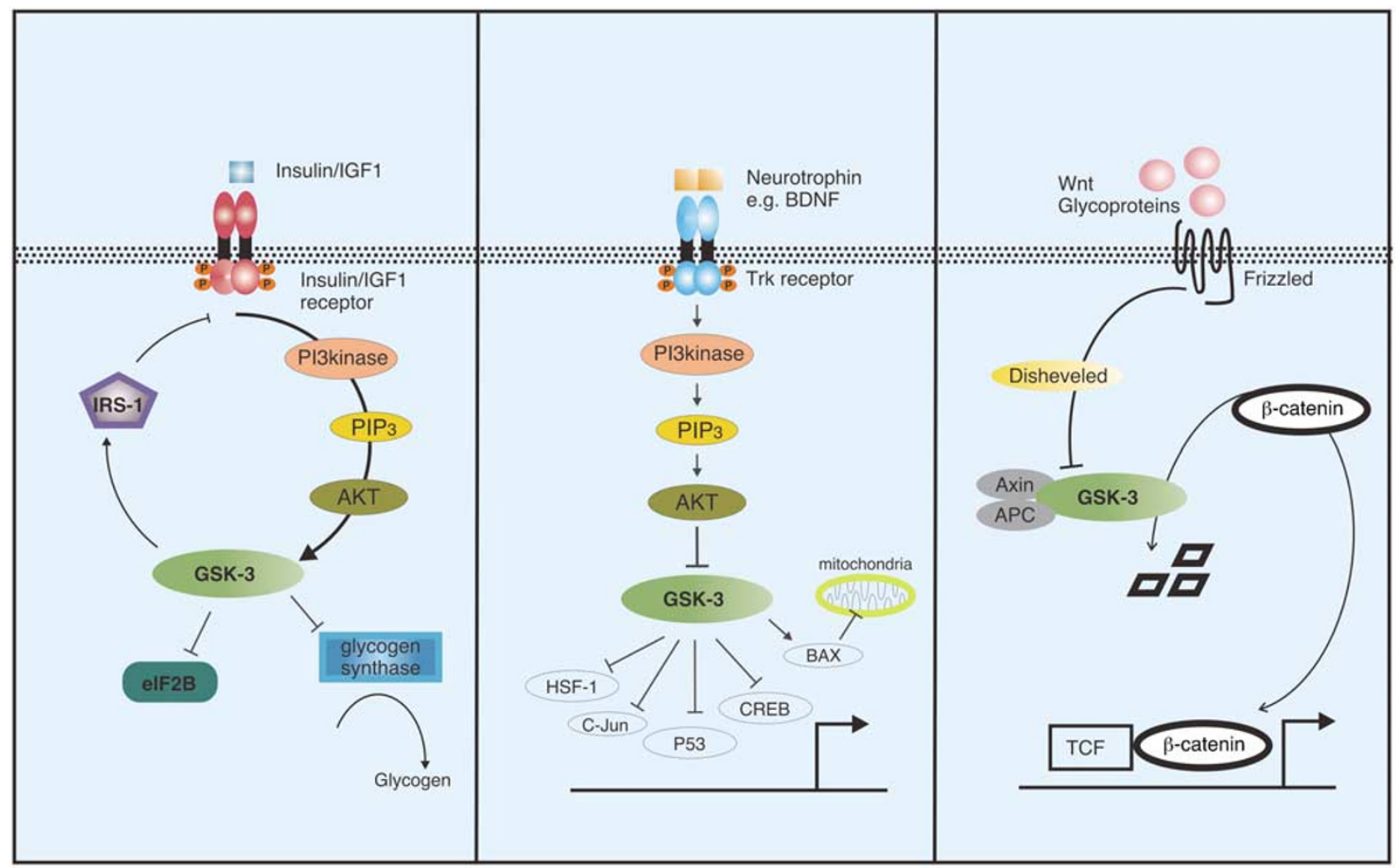

Figure I Glycogen synthase kinase-3 (GSK-3) is a component of diverse signaling pathways. These include insulin/insulin-like growth factor (IGF-I) signaling (left), neurotrophic factor signaling (center), and the Wnt signaling pathway (right). Insulin signaling through its tyrosine receptor kinase (Trk) receptor activates PI3kinase-mediated signaling, resulting in inhibition of GSK-3. Inhibition of GSK-3 activates glycogen synthase and eukaryotic initiation factor 2B (eIF2B) while inhibiting insulin receptor substrate-I (IRS-I; an inhibitor of the insulin receptor). Insulin is generally thought to have minimal effects on CNS neurons; however, IGFI interacting with its cognate receptor appears to have similar functions. Neurotrophins such as brain-derived neurotrophic factor (BDNF) act through Trk receptors A, B, and C to activate PI3kinase, AKT, and inhibit GSK-3. Many effectors have been implicated in GSK-3's neurotrophic effects including transcription factors (eg heat-shock factor-I (HSF-I), C-Jun, P53, and cyclic AMP response element binding protein (CREB)) and recently the proapoptotic bcl-2 family member BAX. In the Wnt signaling pathway, secreted Wnt glycoproteins interact with the frizzled family of receptors and through disheveled mediated signaling inhibit GSK-3. Stability of this process requires the scaffolding proteins Axin and adenomatous polyposis coli (APC). Normally, active GSK-3 phosphorylates $\beta$-catenin leading to its ubquitin-dependent degradation. However, when GSK-3 is inhibited in the Wnt pathway, $\beta$-catenin is not degraded, allowing for its interaction with (T-cell-specific transcription factor) TCF to act as a transcription factor. GSK-3's role in these pathways modulates energy metabolism, provides neuroprotection, and increases neuroplasticity (not mutually exclusive). Thus, our hypothesis is that lithium may act by enhancing these processes through inhibition of GSK-3. However, as detailed in the text, GSK-3 modulates a number of signaling pathways not detailed in the figure. It remains to be determined which pathway(s) may be most relevant to lithium's actions in the treatment of bipolar disorder. 
concert with T-cell-specific transcription factor/lymphoid enhancer factor (TCF/LEF) in the Wnt pathway. Normally, active GSK-3 phosphorylates $\beta$-catenin leading to its ubiquitin-dependent degradation. However, when the Wnt pathway is initiated by secreted wnt glycoproteins binding to the frizzled family of transmembrane receptors, GSK-3 is inhibited. While the interaction is not fully understood, GSK-3 inactivation requires the disheveled protein (Figure 1). Inhibition of GSK-3 results in nonphosphorylated $\beta$ catenin; the levels of which increase resulting in increased $\beta$-catenin-driven gene expression (see Logan and Nusse (2004) for a current review).

In the insulin signaling pathway, insulin, through its tyrosine receptor kinase (Trk) receptor activates PI3kinasemediated signaling resulting in Akt (protein kinase B)mediated inhibition of GSK-3 (Figure 1; Eldar-Finkelman and Ilouz, 2003). Inhibition of GSK-3 activates the enzyme glycogen synthase (which contributes to the synthesis of glycogen and from where GSK-3's name derives) and eukaryotic initiation factor $2 \mathrm{~B}$ (eIF2B) while inhibiting insulin receptor substrate-1 (IRS-1; an inhibitor of the insulin receptor) (Eldar-Finkelman and Ilouz, 2003). Although insulin is currently not known to exert more than minimal effects on CNS neurons, insulin-like growth factor 1 (IGF1) appears to have many similar functions (see Bondy and Cheng (2004) for a discussion of these effects).

In addition to mediating insulin's effects, PI3 kinase and Akt have distinct properties as mediators of the actions of neurotrophic molecules and this represents the most established pathway by which GSK-3 exerts its neurotrophic/neuroprotective effects. Neurotrophic factors are necessary for survival and functioning of neurons. Their actions increase cell survival both by providing necessary trophic support for growth and by exerting inhibitory effects on cell death pathways. The primary actions of neurotrophic factors are mediated via intracellular signaling pathways following binding to a Trk receptor. For instance, the most prevalent neurotrophic factor, brain-derived neurotrophic factor (BDNF), exerts its initial actions by interacting with TrkB. TrkB binding of BDNF initiates TrkB dimerization, which results in autophosphorylation of multiple tyrosine residues in its cytoplasmic domain, and thereafter modulation of intracellular signaling pathways including activation of PI-3 kinase, of which a primary target is Akt (Figure 1). Akt phosphorylates GSK-3, among many other targets. The precise downstream mechanisms that mediate GSK-3's actions in neurotrophic pathways are not fully understood, but are believed to include effectors such as p53 cyclic AMP response element binding protein (CREB), heat-shock factor-1, C-Jun, and Bax (Grimes and Jope, 2001b; Linseman et al, 2004; Watcharasit et al, 2002).

Other kinases that regulate GSK-3 include protein kinase C (PKC), protein kinase A (PKA), and ribosomal S6 kinase (p90RSK). In addition to these functions, GSK-3 has been implicated in amyloid $\beta$ metabolism, control of cell division, regulation of neuronal growth cones, transport of intracellular organelles, and phosphorylation of cytoskeletal proteins tau and MAP1B, among other actions. Thus, the mechanisms of regulation and biological targets of GSK-3 are quite diverse (Figure 1). The precise mechanisms regulating these distinct pathways are an active area of research; however, it is likely that intracellular compart- mentalization allows GSK-3 to accomplish all these functions without significant crosstalk among pathways (Jope and Johnson, 2004).

\section{GSK-3: REGULATION BY LITHIUM AND DIVERSE THYMOLEPTICS}

\section{Lithium}

In 1996 it was discovered that lithium was a direct inhibitor of GSK-3 (Klein and Melton, 1996; Stambolic et al, 1996). This effect was later identified to be through competition for magnesium (Gurvich and Klein, 2002; Ryves and Harwood, 2001). While other group I metal ions (sodium and potassium) do not inhibit GSK-3, the group II ion beryllium does inhibit its activity in a magnesium and ATP competitive manner (Klein and Melton, 1996; Ryves et al, 2002). More recently, zinc has also been identified as a GSK3 inhibitor both directly (Ilouz et al, 2002) and indirectly through phosphorylation (An et al, 2005). Similar to lithium, zinc's direct actions appear to be via competition for magnesium binding (Hagit Eldar-Finkelman, February 2005, personal communication). While it was clear initially that lithium's actions on GSK-3 had major ramifications for the developmental effects of lithium, it was likewise apparent that GSK-3 inhibition could potentially have therapeutic relevance as well (Klein and Melton, 1996; Stambolic et al, 1996). However, it has only been most recently that extensive preclinical research is strongly supporting this hypothesis. Original in vitro measures of lithium's inhibitory potency found $50 \%$ inhibition at concentrations of $1-2$ or $2 \mathrm{mM}$ (Klein and Melton, 1996; Stambolic et al, 1996), a finding that suggests marginal inhibition at therapeutically relevant serum levels of $0.6-$ $1.2 \mathrm{mM}$. However, these data may not accurately reflect in vivo potency, as the magnesium concentrations utilized were much higher than brain intracellular levels. Furthermore, through a 'feedback' mechanism, in vivo inhibition of GSK-3 results in an increase in inhibitory serine phosphorylation. This finding, originally observed by Chuang and co-workers (Chalecka-Franaszek and Chuang, 1999) has been replicated by a number of groups. Proposed mechanisms include GSK-3-regulated decreased activity of protein phosphatase 1 (Zhang et al, 2003), increased activity of PKC (Kirshenboim et al, 2004), or increased Akt activity (Chalecka-Franaszek and Chuang, 1999). Thus, moderate direct inhibition by lithium is amplified through an increase in serine 21/9 phosphorylation. Munoz-Montano et al (1997) originally reported that i.p. injections of lithium could cross the blood-brain barrier in 7-day-old rats. This has been followed by overwhelming evidence to support the statement that therapeutic concentrations of lithium (where rodents had lithium blood levels similar to those observe in patients) result in biologically meaningful GSK-3 inhibition in the mammalian brain (Table 1).

In addition to lithium's direct effects, additional diverse thymoleptics (medications with favorable effects on mood) including valproate, electroconvulsive seizures (ECS; an animal model of electroconvulsive therapy), MAOIs, fluoxetine, imipramine, clozapine, risperidone, and haloperidol regulate GSK-3 indirectly (Table 2). Further, as described in the GSK-3 functions section, estrogen has 
Table I Evidence for Lithium Inhibition of Brain GSK-3 at Therapeutic Doses

\begin{tabular}{|c|c|c|}
\hline $\begin{array}{l}\text { Method of } \\
\text { administration }\end{array}$ & Description & Reference \\
\hline 4 weeks in mouse chow & $\begin{array}{l}\text { Increased GSK-3 } \alpha / \beta \text { serine } 21 / 9 \text { phosphorylation in the } \\
\text { cortex, hippocampus, and striatum }\end{array}$ & $\begin{array}{l}\text { (Roh et al, 2005; De Sarno } \\
\text { et al, 2002) }\end{array}$ \\
\hline Gastric gavage for 3 weeks & Decreased A-beta levels in APP-Swedish transgenic mice & (Phiel et al, 2003) \\
\hline $\begin{array}{l}4 \text { weeks of once daily i.p. } \\
\text { injections }\end{array}$ & Increased $\beta$-catenin surrounding intracranial injection site & (De Ferrari et al, 2003) \\
\hline $\begin{array}{l}9 \text { days of lithium in rat } \\
\text { chow }\end{array}$ & Increased $\beta$-catenin levels in frontal cortex & (Gould et al, 2004a) \\
\hline 7 days in mouse chow & $\begin{array}{l}\text { Increased } \beta \text {-catenin in hypothalmus; increased TCF/LEF- } \\
\text { driven gene expression in amygdala and hippocampus }\end{array}$ & (O'Brien et al, 2004) \\
\hline $\begin{array}{l}\text { Single oral gavage or } 7 \\
\text { months in mouse chow }\end{array}$ & $\begin{array}{l}\text { Decreased A-beta production in PDAPP mice; decreased } \\
\text { A-beta production and plaques in GSK-3 trangenic mice }\end{array}$ & (Su et al, 2004) \\
\hline
\end{tabular}

Only those studies where blood lithium levels were documented to be within the human therapeutic range (serum levels $0.6-1.2 \mathrm{mM}$ ) are included.

mood-modulating effects and regulates GSK-3. It should be pointed out that many diverse drugs have effects on GSK-3, which could suggest nonspecificity of this effect. To the best of our knowledge, few studies have reported the effects of nonthymoleptic medications in their models. This will clearly be necessary to determine the specificity of the effects observed.

\section{Valproate}

Extensive literature has shown that the mood stabilizer valproate (valproic acid) has regulatory effects on GSK-3. However, both direct and indirect effects may be relevant. Chen et al (1999) originally reported that valproate inhibited GSK $-3 \alpha$ and $\beta$ in vitro. This finding has also been replicated by two independent groups (Grimes and Jope, 2001a; Kim et al, 2005; Werstuck et al, 2004). However, other groups have not been able to replicate this in vitro finding (Phiel et al, 2001; Williams et al, 2002; Williams et al, 2005). Hall et al (2002) have found significant inhibition, but only at concentrations above therapeutic levels. It is noteworthy that Werstuck et al (2004) identified derivatives of valproate that were even more potent inhibitors of GSK-3, suggesting that valproate metabolites may potently interact with GSK-3 in vivo. However, it should also be noted that another group was unable to find direct inhibitory effects of valproate metabolites (Williams et al, 2005). It is possible that these contradictory studies of the effects of valproate on GSK-3 may be due to minor differences in substrates or assay conditions. Definitive studies to examine the direct effects of valproate on GSK-3 are clearly warranted.

While the direct effects of valproate on GSK-3 are a matter of debate, valproate exerts effects consistent with inhibition of GSK-3 in cell culture and animal models. Valproate treatment of SH-SY5Y cells at concentrations relevant to treatment results in activation of Akt and an increase in GSK-3 inhibitory phosphorylation (De Sarno et al, 2002). Valproate results in a decrease in phosphorylation of MAP1B in developing neurons, an effect that parallels GSK-3 inhibition (Hall et al, 2002). Valproate is also an activator of the Wnt signaling pathway, as judged by its effect of increasing $\beta$-catenin in cell culture (Chen et al, 1999; Phiel et al, 2001) and in the rat brain following 9 days of administration (Gould et al, 2004a). Acute valproate administration to mice prevents hypoxia-induced decreases in phosphorylation of GSK-3 (Roh et al, 2005). Relatedly, Li et al (2002) found that another mood-stabilizing anticonvulsant, lamotrigine, similar to lithium and valproate, attenuates staurosporine and heat-shock-induced caspase- 3 activity in a cell line overexpressing GSK-3 $\beta$. Thus, valproate clearly has inhibitory effects on GSK-3-regulated pathways, but it is debatable whether this is direct, indirect, or both direct and indirect.

\section{Antidepressants}

An analysis of the ability of the serotonergic system to regulate GSK-3 was recently reported by Li et al (2004). This group utilized a number of different mechanisms (including the administration of common antidepressant medications), and Western analysis, to show that acute increases in serotonin levels modulate GSK- $3 \beta$ in the mouse brain.

Administration of the serotonin release stimulator and reuptake inhibitor, $d$-fenfluramine increased GSK-3 serine 9 phosphorylation in the prefrontal cortex, hippocampus, and striatum. The monamine oxidase inhibitor clorgyline had no effect when administered on its own, but enhanced GSK$3 \beta$ phosphorylation when administered prior to d-fenfluramine. Similar results were observed with both fluoxetine and imipramine in the prefrontal cortex ( $\mathrm{Li}$ et al, 2004). These imipramine Western blot findings were recently confirmed by immunohistochemistry and extended to show that administration of imipramine to mice prevents hypoxia-induced decreases in GSK-3 phosphorylation (Roh et al, 2005).

\section{Electroconvulsive Seizures}

Electroconvulsive therapy (ECT) is generally considered the most effective treatment for depression. Although often not as well appreciated, ECT is an efficacious treatment for mania as well (Mukherjee et al, 1994). Electroconvulsive seizure (ECS), an animal model of ECT, has been shown to 
Table 2 Diverse Classes of Mood Stabilizers and Antidepressants have Effects on GSK-3

\begin{tabular}{|c|c|c|c|c|}
\hline $\begin{array}{l}\text { Drug or } \\
\text { manipulation }\end{array}$ & $\begin{array}{l}\text { Involvement in } \\
\text { mood disorders }\end{array}$ & Effects on GSK-3 & Study design & $\begin{array}{l}\text { References (see text for } \\
\text { complete references) }\end{array}$ \\
\hline Lithium & $\begin{array}{l}\text { Primary treatment } \\
\text { for bipolar } \\
\text { disorder }\end{array}$ & $\begin{array}{l}\text { Direct inhibitor of GSK-3 by } \\
\text { competition for magnesium }\end{array}$ & In vitro, cell culture, in vivo & (Klein and Melton, 1996) \\
\hline Valproate & $\begin{array}{l}\text { Primary treatment } \\
\text { for bipolar } \\
\text { disorder }\end{array}$ & $\begin{array}{l}\text { Some studies suggest direct } \\
\text { inhibition; many studies } \\
\text { suggest indirect inhibition }\end{array}$ & In vitro, cell culture, in vivo & $\begin{array}{l}\text { (De Sarno et al, 2002; Gould } \\
\text { et al, 2004a; Chen et al, 1999) }\end{array}$ \\
\hline Antidepressants & $\begin{array}{l}\text { Treatment for } \\
\text { depression } \\
\text { (unipolar and } \\
\text { bipolar) }\end{array}$ & $\begin{array}{l}\text { Fluoxetine, imipramine, and } \\
\text { clorgyline increase inhibitory } \\
\text { phosphorylation in the mouse } \\
\text { brain }\end{array}$ & Acute injections in mice & (Roh et al, 2005; Li et al, 2004) \\
\hline ECS & $\begin{array}{l}\text { Model of ECT, the } \\
\text { most efficacious } \\
\text { therapy for severe } \\
\text { refractory } \\
\text { depression; also a } \\
\text { successful } \\
\text { treatment for } \\
\text { refractory mania }\end{array}$ & $\begin{array}{l}\text { Increases inhibitory } \\
\text { phosphorylation of GSK-3 and } \\
\beta \text {-catenin in rats }\end{array}$ & $\begin{array}{l}\text { Single (p-GSK-3) and multiple ( } \beta \text { - } \\
\text { catenin) administrations to rats }\end{array}$ & $\begin{array}{l}\text { (Roh et al, 2003; Madsen et al, } \\
\text { 2003) }\end{array}$ \\
\hline Amphetamine & $\begin{array}{l}\text { Can precipitate } \\
\text { mania in } \\
\text { susceptible } \\
\text { individuals; used as } \\
\text { a lithium } \\
\text { responsive rodent } \\
\text { model of mania }\end{array}$ & $\begin{array}{l}\text { Increases inhibitory } \\
\text { phosphorylation of GSK-3 in } \\
\text { the brain after I } 5 \text { min; } \\
\text { decreases inhibitory } \\
\text { phosphorylation after } 90 \text { min; } \\
\text { acute behavioral effects } \\
\text { prevented by GSK-3 inhibition }\end{array}$ & Studies were performed in mice & $\begin{array}{l}\text { (Svenningsson et al, 2003; } \\
\text { Beaulieu et al, 2004) }\end{array}$ \\
\hline Zinc & $\begin{array}{l}\text { Shown in a } \\
\text { preliminary } \\
\text { double-blind study } \\
\text { to be an effective } \\
\text { adjunct treatment } \\
\text { for depression } \\
\text { (Nowak et al, } \\
\text { 2003a). } \\
\text { Antidepressant-like } \\
\text { effect in the FST } \\
\text { and olfactory } \\
\text { bulbectomy rodent } \\
\text { models }\end{array}$ & $\begin{array}{l}\text { Direct inhibitor of GSK-3 by } \\
\text { competition for magnesium }\end{array}$ & In vitro and cell culture & (llouz et al, 2002) \\
\hline
\end{tabular}

See text for discussion and complete references. 
alter phosphorylation of GSK-3. Roh et al (2003) found that a single administration of ECS to rats resulted in an increase in brain GSK-3 $\beta$ phosphorylation after $10 \mathrm{~min}$. In a followup study, this group provided evidence that this phosphorylation may occur in an Akt-dependent manner (Kang et al, 2004a). Madsen et al (2003) studied the effects, in rats, of once daily ECS on expression of the GSK-3 target $\beta$-catenin. They found that 10 days of ECS increased $\beta$-catenin levels in the subgranular zone of the hippocampal dentate gyrus, and that $\beta$-catenin strongly colocalized with $\operatorname{BrdU}$ (a marker of cell proliferation). These data led the authors to postulate that the increase in $\beta$-catenin may be responsible for ECSinduced increased neurogenesis (Madsen et al, 2003; Malberg et al, 2000). They also found that ECS increased the levels of Wnt-2, a ligand that activates $\beta$-catenindependent Wnt signaling through inhibition of GSK-3 (Madsen et al, 2003).

\section{Antipsychotics}

In addition to their use in the treatment of psychosis antipsychotics (both typical and atypical) have utility for the treatment of bipolar disorder, and an increasing number of these drugs are FDA approved for this indication. The effect of clozapine on GSK-3-mediated signaling pathways has been examined in cell culture. Kang et al (2004b) found that similar to antidepressants, ECS, lithium, and valproate, clozapine administration increases inhibitory (serine 9) phosphorylation of GSK-3 $\beta$. This finding was coincident with an increase in nuclear $\beta$-catenin levels. While this study did not address the effects of clozapine in vivo, chronic treatment of mice with haloperidol increased serine 9 phosphorylation of GSK-3 $\beta$ (Emamian et al, 2004). The authors postulated that this was via an AKT-dependent mechanism, as the same treatment increased AKT phosphorylation. Chronic treatment may be required, as a study by another group found that a single injection of haloperidol to mice did not increase phosphorylation of GSK-3 $\beta$ in the frontal cortex $1 \mathrm{~h}$ following administration (Li et al, 2004). Most recently, Alimohamad et al (2005) found that administration of haloperidol, risperidone, or clozapine increased levels of $\beta$-catenin, GSK-3 total protein, and GSK-3 $\beta$ serine 9 phosphorylation in regions of the rat brain. They additionally examined the effects of a single, and 28 daily injections of haloperidol and risperidone, finding that only the chronic administration paradigm resulted in increases (Alimohamad et al, 2005). The initial Western blot findings were confirmed with immunohistochemistry while additionally identifying increased nuclear $\beta$-catenin immunoreactivity. The protein increases were also found to occur following administration of the D2/D3 receptor antagonist raclopride. Coupled with their previous results, this finding suggests that the mechanism of action involves inhibition of the D2 receptor (Alimohamad et al, 2005).

\section{RECENT SUPPORT FROM ANIMAL BEHAVIORAL MODELS AND GENETIC STUDIES}

Recent evidence suggests that many of the behavioral effects of lithium in rodent models may be due to inhibition of
GSK-3. Lithium has long been documented to attenuate amphetamine hyperactivity in rodents, having become one of the most popular and reproducible models of antimanic drug efficacy (see Einat et al (2003) for a discussion). The hyperactivity is attenuated by antipsychotic drugs as well as anticonvulsants often utilized for the treatment of bipolar disorder (Lamberty et al, 2001). It also has validity in the sense that amphetamine commonly precipitates manic episodes in susceptible individual who suffer from bipolar disorder - an effect that may be attenuated by lithium (Huey et al, 1981; van Kammen et al, 1985; Van Kammen and Murphy, 1975). Further, the motoric changes in activity present in bipolar disorder are among the most defining characteristics of the illness, ranging from near catatonic immobility to the profound hyperactivity of manic states. Similarly, loss of motivation is one of the central features of depression and anhedonia/extreme hedonia are among the most defining characteristics of bipolar depression and mania, respectively. In this context, it is noteworthy that the midbrain dopamine systems are known to play critical roles in regulating not only motoric activity but also motivational and reward circuits. On these grounds it is perhaps surprising that the dopaminergic system has not traditionally received as much attention as serotonergic or noradrenergic mechanisms in studies addressing the pathophysiology of bipolar disorder and depression.

Beaulieu et al (2004) have recently found in mice that amphetamine induced increases in activity is mediated, at least in part, through a GSK-3 dependent mechanism. This group reported that amphetamine administration to mice resulted in a reduction in the phosphorylation of GSK- $3 \alpha$ and GSK-3 $\beta$ in the striatum, an effect opposite to lithium administration. They additionally reported that the endogenous hyperactivity found in dopamine transporter (DAT) knockout mice was attenuated by administration of lithium, in addition to five other GSK-3 inhibitors. Furthermore, in mice lacking one copy of GSK-3 $\beta$ amphetamine hyperactivity was decreased. Pharmacological inhibition of GSK-3 also attenuates amphetamine hyperactivity in rats (Gould et al, 2004b).

O'Brien et al (2004) identified another lithium-dependent behavior in mice; they found that lithium treatment results in an antidepressant-like effect (increased activity) in the forced swim test (FST). Hagit Eldar-Finkelman and coworkers have found similar results following intraventricular injection of lithium to mice (unpublished personal communication, February 2005). The FST, developed by Porsolt et al (1977) is widely utilized as a behavioral measure of antidepressant efficacy. It has recently been scrutinized due to the fact that the measure has been validated with monoaminergic acting antidepressants and as such has the potential to miss antidepressants with novel mechanisms. Furthermore, a number of disparate neurobiological mechanism could lead to increased activity. However, the specificity of the effect of lithium is supported by studies utilizing alternate GSK-3 inhibitors. Specifically, Kaidanovich-Beilin et al (2004) reported antidepressant-like effects in the FST paradigm following intracerebral ventricle injections in mice of L803-mts (a peptide substratecompetitive inhibitor). Gould et al (2004b) similarly found antidepressant-like effects in the FST following peripheral administration of AR-A014418, a selective ATP-binding site 
inhibitor, to rats. Furthermore, O'Brien et al (2004) examined the behavioral effects of knocking out a single copy of GSK-3 $\beta$, observing in these animals the same antidepressant-like behavior in the FST induced by pharmacological inhibition of GSK-3.

Supportive evidence comes from behavioral studies of elemental zinc, another inhibitor of GSK-3 $\beta$ (Ilouz et al, 2002). Zinc has antidepressant-like properties in the FST and olfactory bulbectomy model in rats (Kroczka et al, 2001; Kroczka et al, 2000; Nowak et al, 2003b), and low (ineffective) doses of zinc combined with ineffective doses of antidepressants likewise have antidepressant-like effects in preclinical models (Kroczka et al, 2001; Szewczyk et al, 2002; Wyska et al, 2004). Furthermore, in a recent placebocontrolled clinical study, adjunctive treatment with Zinc had antidepressant effects (Nowak et al, 2003a). These data suggest the possibility that zinc may exert these effects through inhibition of GSK-3; however, zinc has other biological effects, including antagonism of NMDA receptors (see Quiroz et al (2004) for a review), that require consideration.

Recent genetic evidence is also supportive. GSK-3 $\alpha$ and $\beta$ are mapped to human $19 \mathrm{q} 13.1-13.2$ and $3 \mathrm{q} 13.3-21.1$, respectively (Hansen et al, 1997; Shaw et al, 1998), both of which have been marginally linked to bipolar disorder (Badenhop et al, 2002). Within a population of nonbipolar subjects, Russ and co-workers studied sequence variations of the GSK- $3 \beta$ gene and promoter. They did not identify any sequence variations in the gene; however, they reported five promoter single-nucleotide polymorphisms (SNPs), two of which were present at a rate over $10 \%(18$ and 41$)$. One of these common promoter polymorphisms, $(-50 \mathrm{~T} / \mathrm{C})$, has been studied by Benedetti and co-workers. They reported that this polymorphism is associated with response to lithium in a group of 88 bipolar disorder type I patients (Benedetti et al, 2005). Specifically, the carriers of the T/T genotype improved less on lithium than either the $\mathrm{T} / \mathrm{C}$ or $\mathrm{C} / \mathrm{C}$ groups.

This group has additionally studied other factors that may be associated with the $-50 \mathrm{~T} / \mathrm{C}$ polymorphism. In a sample of 185 Italian bipolar patients, they identified an earlier age of onset associated with the T genotype $(P=0.0047)$ (Benedetti et al, 2004a). A follow-up study of another group of patients confirmed the age of onset effect of the T genotype (Benedetti et al, 2004b). They further identified a second association with an antidepressant response to sleep deprivation. A total of 60 bipolar depressed patients were administered a night of total sleep deprivation followed by a night of undisturbed sleep. Patients with the $\mathrm{C} / \mathrm{C}$ genotype had better acute effects to total sleep deprivation, and a subsequent higher relapse following one night of recovery sleep. These findings led Benedetti et al (2004b) to speculate that the $\mathrm{C} / \mathrm{C}$ genotype may characterize a milder form of the disorder, with later age of onset and more responsivity to treatment. An initial family-based association study (transmission disequilibrium test) by this same group was negative (Tubazio et al, 2004), which could be interpreted as suggesting that GSK-3 polymorphisms may be associated more strongly with bipolar disorder endophenotypes (Gottesman and Gould, 2003). This supports a hypothesis that there exists a genotype-environment interaction (Benedetti et al, 2004b; Lenox et al, 2002).
It is important to keep in mind that the general caveats of genetic association studies are fraught with poor reproducibility due to population stratification artifacts. The associations to response to lithium and sleep deprivation both require replication in a distinct patient group. Further, while Benedetti and co-workers were able to reproduce their age of onset findings in a separate sample, it is likely that the second sample was derived from a similar population.

\section{FUNCTIONS OF GSK-3 RELEVANT TO MOOD STABILIZATION}

It is not simply the finding that GSK-3 is inhibited by lithium (and other thymoleptics), which makes it of such interest. GSK-3 is involved in many biological processes that could have relevance for the treatment of mood episodes. These functions include (but are not limited to) regulation of monaminergic signaling, neuroprotection (or enhancing neuroplasticity or cellular resilience), regulation of circadian rhythms, modulating estrogen and glucocorticoid activity, or regulation of brain metabolism. As the underlying neurobiology of bipolar disorder is currently unclear, it is difficult to eliminate any of these possibilities.

\section{Regulation of Monoaminergic Signaling}

Regulation of monaminergic signaling has long been implicated in the mechanism of action of antidepressant medications, as well as the pathophysiology of mood disorders (Bunney and Davis, 1965; Schildkraut, 1965). This conclusion arose initially from observations that the antihypertensive reserpine, which decrease brain monoamine levels, could precipitate depression and that MAOIs and tricyclics increased synaptic monamine levels. Rapid lowering of serotonin, via tryptophan depletion, predictably results in the onset of depression symptoms in remitted depressed patients being treated with medications (Charney, 1998). Thus, in toto, the data suggests that while other factors are undoubtedly also involved, the monoaminergic systems do play important roles in the pathophysiology and treatment of mood disorders.

Recent data have suggested that intracellular responses to both serotonergic and dopaminergic inputs are modulated by GSK-3. As discussed in the section on the effects of antidepressants on GSK-3, increasing serotonin levels, through a variety of pharmacological mechanisms, results in inhibitory phosphorylation of mouse frontal cortex, hippocampal, and striatal GSK-3 $\beta$ as witnessed by increases in serine 9 phosphorylation (Li et al, 2004; Roh et al, 2005). The effect appears to be through 5HT1A receptors. An antagonist of this receptor, WAY100635, attenuates GSK-3 $\beta$ inhibition and 8-OH-DPAT (5HT1A agonist) was able to increase serine 9 phosphorylation (Li et al, 2004). Conversely, administration of the 5HT2 receptor antagonist LY53857 resulted in an increase in phosphorylation. Further experiments utilizing both LY53857 and serotonin agonists further supported the finding that the effects of serotonin agonism on phosphorylation of GSK-3 serine 9 are mediated by 5HT1A receptors, while activation of the 5HT2 receptor attenuates this effect (Li et al, 2004). These findings are particularly noteworthy since these are precisely the same serotonergic system changes (viz. enhancement of 5HT1A throughput and antagonism/down- 
regulation of $5 \mathrm{HT} 2$ receptors) that have been most implicated in the mechanisms of action of a variety of antidepressant treatments (Blier and Abbott, 2001).

GSK-3 has also been implicated as being effected by dopaminergic signaling. Beaulieu et al (2004) showed that phosphorylated striatal GSK- $3 \alpha$ and $\beta$ levels decreased 90 min following injection of amphetamine, an effect that was not observed at $30 \mathrm{~min}$, and paralleled increases in Akt phosphorylation. The action on GSK-3 appears to be independent of the effects of cyclic AMP. In dopamine transporter knockout mice, administration of $\alpha \mathrm{MTP}$ to deplete catecholamine synthesis or raclopride (D2 receptor antagonist) increased phosphorylation. However, this effect was not observed with the D1 antagonist. Experiments in mice have conversely shown that amphetamine increases serine 9 phosphorylation after $15 \mathrm{~min}$ in the frontal cortex and striatum, suggesting that the effects may be time dependent (Svenningsson et al, 2003). The findings that serotonin, dopamine, and amphetamine regulate GSK-3 provides an important link between a critical signaling molecule and neurochemical brain circuits likely involved in the pathophysiology of bipolar disorder.

\section{Neuroprotection}

An extensive literature has found that lithium exerts neurotrophic/neuroprotective effects in vitro, in animal models, and perhaps even in humans. Lithium has been found to protect neuronal cell cultures against many varied agents including excessive glutamate, A beta, serum deprivation, colchicine, low potassium, and prion related protein, among many others (see Chuang et al (2002) and Manji et al (1999) for a review). Supporting the notion that these cell culture observations have true physiological relevance, lithium is neuroprotective in many animal models including ischemia, Huntington's disease, HIV gp120 envelope protein injection (a model of HIVassociated dementia), and radiation (see Chuang et al (2002) and Manji et al (1999) for a review). Proof from welldesigned epidemiological and clinical studies will be required to validate whether these actions are clinically relevant for the treatment of mood disorders. In this regard, prospective studies designed to address this question found that 4 weeks of lithium treatment increases human gray matter (Moore et al, 2000b) and levels of the neuronal marker $N$-acetyl aspartate (NAA) (Moore et al, 2000a); both of which are consistent with the neurotrophic/neuroprotective effects that have been observed in preclinical models.

It has further been hypothesized that the neuroprotective effect of lithium may be related to clinical efficacy of the drug (Manji et al, 1999). Methodologies to investigate structural and functional deficits within the human brain have exponentially increased in recent years allowing for a more complete and intensive analysis of potential deficiencies in the brains of patients suffering from neuropsychiatric disorders and it is now possible to discern relatively subtle differences in cerebral blood flow, receptor density, or in macroscopic brain structure (Seibyl et al, 2004). Likewise, postmortem studies of the brain have been enhanced with technological advances that allow for relatively unbiased observations of cell density, morphology, and size (Lopez et al, 2004). The functional and morphometric findings in mood disorders have been extensively reviewed elsewhere (Drevets, 2000; Manji et al, 2001; Manji et al, 2000; Rajkowska, 2002).

In brief, the brains of patients with mood disorders show both macroscopic and microscopic changes that separate them from healthy individuals. While these findings are not yet diagnostic, many are now becoming consistent. These include studies utilizing structural imaging, which report a decrease in frontal and temporal gray matter and an increase in ventricular size in patients with mood disorders (Drevets, 2000). Many studies also report a decrease in the size of other neuronal structures, including the hippocampus and portions of the basal ganglia (Drevets, 2000; Rajkowska, 2002). White matter hyperintensities (WMH) on T2-weighted MRI are also observed at a greater incidence in the brains of mood disorder patients, especially bipolar disorder (Altshuler et al, 1995). Functional imaging has also revealed multiple abnormalities of regional cerebral blood flow and glucose metabolism in these same limbic and prefrontal cortical structures (Drevets, 2000; Manji et al, 2001).

Recent postmortem studies using unbiased stereology techniques and additional improved technologies (Lopez et al, 2004) have identified a number of changes including a decreased size and/or density of neurons, and decreased number and density of glial cells in regions of the anterior cingulate cortex, orbital frontal cortex and dorsal lateral prefrontal cortex, as well changes in the hippocampus and amygdala (see Rajkowska (2002) for a complete review of these findings).

An extensive series of literature has also suggested that it is likely that lithium may exert some, if not the majority, of its neuroprotective effects through inhibition of GSK-3. (see Chuang et al (2002), Jope and Bijur (2002) and Manji et al, 1999) for a review). Specifically, in most systems over activity of GSK-3 is proapoptotic, while inhibiting GSK-3 is antiapoptotic. For example, increased activity of GSK-3 in a number of cell types increases apoptosis, or is correlated with apoptosis in neuronal cells (Bijur et al, 2000; Bijur and Jope, 2001; Hetman et al, 2000; Maggirwar et al, 1999; Pap and Cooper, 1998; Takashima et al, 1993). Conversely, decreasing GSK-3 activity either with a protein inhibitor, antisense nucleotides, utilizing an inactivated form of GSK-3, or with administration of lithium or alternate GSK-3 inhibitors prevents these effects (Bijur and Jope, 2001; Hetman et al, 2000; Maggirwar et al, 1999; Pap and Cooper, 1998; Takashima et al, 1993). GSK-3 activity also increases in the rat cortex following focal cerebral ischemia (Bhat et al, 2000).

Thus, both neuroimaging and postmortem investigations suggest that the pathology of mood disorders may involve cell- and structural-based impairments in function and plasticity, consequences that perhaps could be modified by the neurotrophic effects of medications (Manji et al, 2000). Given GSK-3's position as a primary regulator of apoptosis, it is likely that the neuroprotective effects of lithium are due, at least in part, to GSK-3 inhibition (Jope and Bijur, 2002; Manji et al, 1999).

\section{Neurohormone Regulation: Estrogen and Glucocorticoids}

A great deal of evidence suggests that gonadal steroids, and in particular estrogen, may play a role in the pathophysio- 
logy and/or treatment of mood disorders. For example, while major depressive disorder effects $10 \%$ of men, it effects up to two to three times as many women, a figure that is only accurate following the onset of puberty. Times of estrogen hormone fluctuation, such as during the postpartum and premenstrual periods, are associated with mood changes (mania and depression) (Bloch et al, 2003; Payne, 2003). However, little evidence suggests that absolute hormonal levels of progesterone and estrogen are different from controls (Bloch et al, 2003). This supports a notion that downstream effects of these hormones, such as receptor desensitization or abnormal signaling cascades, are responsible for the abnormal mood states. Furthermore, recent studies have described the role of gonadal steroids (especially estrogen) in neuroprotection, cellular resilience, and neural plasticity - effects similar to those observed with mood stabilizers (Lee and McEwen, 2001; Payne, 2003; Ramirez et al, 2001).

It is thus noteworthy that estrogen has been shown to regulate GSK-3. Estrogen administered to adult ovariectomized rats increased hippocampal serine GSK-3 phosphorylation (Cardona-Gomez et al, 2004). This group further reported that the effects occurred in primary hippocampal cultures, and that GSK-3 was colocalized in a complex that included estrogen receptor $\alpha(E R \alpha)$ and $\beta$-catenin. Kouzmenko et al (2004) similarly immunoprecipated ER $\alpha$ and $\beta$ catenin, finding that this interaction was enhanced by the addition of estrogen. They further identified that that $\operatorname{ER} \alpha$ and $\beta$-catenin could act in concert to drive gene expression using both TCF/LEF-binding element (TBE; topflash construct) and estrogen response element (ERE) reporting vectors. Using the chromatin immunoprecipitation (ChIP) assay they also identified interactions of ER $\alpha$ and $\beta$-catenin antibodies with genes containing TBE and ERE, respectively. These data are consistent with a recent finding, albeit in non-neuronal tissue, that concomitant lithium and estrogen administration to ovariectomized mice results in an increase in estradiol-induced proliferative and morphogenetic changes in the uterus (Gunin et al, 2004).

Current theories suggest that stress and reactivity to stress, via modulation of the hypothalamic pituitary adrenal (HPA) axis, may be a major pathogenic mechanism underlying susceptibly to recurrent mood disorders and a likely contributor to the neuroimaging and postmortem abnormalities observed. This pathway represents the primary 'stress' pathway in humans and other mammals, whereas the lateral ventricular nucleus of the hypothalamus releases corticotropin-releasing hormone/factor (CRH/F), which stimulates the production of adrenocorticotropin releasing hormone (ACTH) by the pituitary. This latter hormone stimulates the production of glucocorticoids by the adrenal gland. Cortisol is considered a primary stress hormone of the body, having varied effects on metabolism, neurovegetative behaviors of organisms, and a multitude of effects on the functions of neurons and neuronal systems. Smith and Frenkel (2004) reported an interaction between glucocorticoids and $\beta$-catenin. Their studies, in osteoblastlike cultures, showed that dexamethasone administration resulted in a decrease in $\beta$-catenin levels and inhibition of TCF/LEF-mediated transcription. Ohnaka et al (2005) have reported similar results. They found that Wnt3a-stimulated increases in $\beta$-catenin in primary cultured human osteo- blasts were attenuated by dexamethasone administration. If these studies hold true in the brain, they may provide an interesting nexus between the HPA axis and $\beta$-catenin/GSK-3.

\section{Regulation of Circadian Rhythms}

Circadian rhythm abnormalities have been extensively studied in mood disorders for decades. Converging evidence suggests that abnormal circadian rhythms play a role in bipolar disorder (Bunney and Bunney, 2000; Healy and Waterhouse, 1995; Klemfuss, 1992; Wehr and WirzJustice, 1982): (1) circadian abnormalities (period shortening) are well documented in patients with bipolar disorder, (2) nonpharmacological treatments (such as sleep deprivation, adjustment of sleep cycles, and light therapy) are often helpful in the treatment of mood disorders, (3) Sleep deprivation is a highly efficacious - but shortterm-treatment for the depressive phase of bipolar disorder, (4) sleep deprivation (albeit more than just a circadian manipulation) is a common precipitant of the manic phases of bipolar disorder, and finally (5) there exists an extensive body of data describing lithium's effects on circadian rhythms. Lithium has been shown in numerous studies to modify the phase and period of circadian rhythms in a variety of species, ranging from unicellular organism and insects to mice and even humans (see Klemfuss (1992) for a complete review). Most consistently, lithium has been shown to lengthen the circadian period across species. This finding, combined with the previously mentioned reports of alternative methods that modify circadian cycles proving effective in the treatment of mood disorders, led to the suggestion that some of the therapeutic effects of lithium may also arise, at least in part, from its effect on the circadian cycle length (Wehr and Wirz-Justice, 1982).

Data suggesting that GSK-3 may represent lithium's target responsible for alterations in circadian cycles derived initially from Drosophila studies. Martinek et al (2001) identified the Drosophila orthologue of GSK-3 $\beta$, SHAGGY, as a component of the circadian cycles. Overexpression of SHAGGY lengthened the Drosophila free-running circadian cycle (Martinek et al, 2001). Additionally, a decrease in SHAGGY activity resulted in an increase in circadian period length (Martinek et al, 2001), the effect (increase in circadian period) that has been noted in numerous species, including Drosophila, after treatment with lithium (Klemfuss, 1992; Padiath et al, 2004).

It should be noted, however, that while there are many similarities between the molecular components of circadian cycles in mammals and Drosophila, there are many differences as well (Reppert and Weaver, 2000). Beginning to address this, Iwahana et al (2004) investigated the effects of lithium on GSK-3 in the mouse suprachiasmatic nucleus (SCN). They found that the serine 9 phosphorylation of GSK-3 and total GSK-3 $\alpha$ ( $\beta$ was found only at a low level) protein levels were regulated at certain points during the circadian cycle, and that lithium administration had inhibitory effects on their levels and activity. These effects were coincident with an affect of lengthening of the circadian cycle, and appeared specific for the SCN, as similar effects were not observed in the arcuate nucleus. As mentioned in an earlier section response to sleep depriva- 
tion has been associated with a GSK-3 $\beta$ promoter polymorphism (Benedetti et al, 2004b).

Additional studies in mammals are eagerly awaited. However, GSK-3 represents a possible molecular target for the actions of lithium on circadian cycles, and even if the circadian effects of lithium are not relevant to the treatment of mood disorders, it still may remain a valuable in vivo marker of GSK-3 inhibition.

\section{Metabolic Effects}

Another consideration is that GSK-3's role in the regulation of cellular energy metabolism may be of importance. As described, GSK-3 was initially named based upon its role in the phosphorylation of glycogen synthase, thereby acting as a critical regulator of insulin's effects on the insulin/ PI3kinase/Akt pathway. Inactivation of GSK-3 leads to synthesis of glycogen, activation of the insulin receptor through decreased phosphorylation of IRS-1, and decreased phosphorylation and activation of eukaryotic initiation factor (eIF)-2B (Cohen and Goedert, 2004; Eldar-Finkelman and Krebs, 1997; Welsh and Proud, 1993). While insulin may not have a major action on most brain areas, IGF-1 is active and, in many ways, mimics the effects of insulin (Bondy and Cheng, 2004). Lithium has been noted to, among other metabolic effects, increase glycogen concentrations in the rodent brain (Plenge, 1976). However, lithium has inhibitory effects on metabolic enzymes fructose 1,6-bisphosphastase (FBPase) and phosphoglucomutase (PGM) that should be considered (Gould et al, 2004c).

A number of metabolic changes have been noted in the brains of patients with mood disorders. These include elevation of resting cerebral blood flow and glucose metabolism in the amygdala and left medial thalmus (Drevets, 2000). However, a decrease in cerebral blood flow and metabolism has been noted in the caudate and the subgenual prefrontal cortex (see Drevets (2000) for a complete review of these data). The utilization of glucose additionally represents a potential role in neuroprotection. For example, work by Sapolsky and colleagues has strongly implicated efficiency of glucose utilization and uptake with the susceptibility of neurons to harmful stimuli (neuronal resilience) (see Sapolsky (1996) for review). GSK-3's role in these processes may be of relevance and, although not extensively investigated, GSK-3 inhibition may at least in part mediate neuroprotective effects through effects on cellular metabolism.

\section{THERAPEUTIC IMPLICATIONS}

Thus, precisely how GSK-3 inhibition could be exerting actions in the treatment of bipolar disorder is a matter of considerable interest. While it is possible that multiple effects of inhibition of this enzyme may be relevant (or that different effects may have a role in antidepressant $v s$ antimanic actions), the most parsimonious explanation suggests a single biological process or pathway that would be targeted to exert therapeutic effects. Given the large number of cellular targets of GSK-3, a number of prospects exist. As discussed in this review, these include neuropro- tective effects, modulation of circadian rhythms, modulation of monaminergic-mediated signaling events, response element binding of neurohormones and $\beta$-catenin, and metabolic effects. GSK-3's role in these processes may provide a link between seemingly diverse processes regulated by lithium (or that are abnormal in bipolar disorder).

Additionally discussed, diverse thymoleptics including lithium, valproate, ECS, antidepressants, antipsychotics, and estrogen regulate GSK-3 directly or by modulating phosphorylation (Table 2). Thus, GSK-3 may represent a common pathway on which these medications converge, and perhaps, a target for novel medications. Of course, in the framework of the development of novel therapeutics, this discussion is moot unless the potential exists to clinically test the hypothesis that inhibiting GSK-3 has thymoleptic properties. Indeed, true validation - especially considering the less than ideal animal models for bipolar disorder and depression - will only arise from clinical trials of brain penetrant and selective novel GSK-3 inhibitors.

Fortunately, there exists major pharmaceutical interest in the development of novel, potent inhibitors of GSK-3, and most large companies have a GSK-3 inhibitor development program (see Cohen and Goedert (2004) for a review). The primary impetus for these inhibitors is generally not for the treatment of mood disorders, but rather for the treatment of other diseases, especially Alzheimer's disease and diabetes (Cohen and Goedert, 2004). However, regardless of the reason for development, GSK-3 inhibitors are actively being developed and will expectantly be available for bipolar disorder treatment trials in the future. The majority of these molecules act by inhibiting the interaction between ATP and GSK-3. Many of these inhibitors have had some effects on other kinases, most commonly cyclin-dependent kinases (CDKs). However, more recent efforts have reported increased specificity. There are additionally attempts to develop inhibitors that are non-ATP competitive. For example, Eldar-Finkelman and co-workers have reported the development of L803-mts, a substrate competitive inhibitor that is active in rodent models of both diabetes and depression (Kaidanovich-Beilin et al, 2004; Plotkin et al, 2003). Competition for substrate, and through other non-ATP competitive approaches, has the potential to inhibit GSK-3 action in some pathways but not others. As would be expected from a molecule with such a vast array of intracellular functions, inhibition of GSK-3 could be predicted to result in deleterious side effects (Cohen and Goedert, 2004). Most concerning may be the role of $\beta$ catenin and the Wnt signaling pathway in promoting tumor growth. Current epidemiological evidence and 50 years of clinical use does not implicate long-term lithium use with an increased risk of any type of cancer (Cohen et al, 1998). Furthermore, lithium administration to mice with a mutation in the APC protooncogene protein does not result in an increase in the number of colonic tumors (Gould et al, 2003).

For far too long, the accepted outcome of treatment for mood disorder has been incomplete remission in some patients who are responsive to the current pharmacopia. As clinical researchers, we cannot continue to be accepting of the status quo. The ultimate goal must be to strive for full remission in all patients. To reach this goal, truly novel 
medications must be developed. It is likely that future strategies will account for disease heterogeneity, subclassifying and subsequently treating mood disorders based upon endophenotypes (Gottesman and Gould, 2003). Understanding the complex neurobiology of these disorders will be a major advancement. This will certainly not be fully complete until the majority of susceptibility genes have been identified. However, in the interim, advances in understanding targets of current medications will allow the ability to test novel compounds for efficacy in proof of concept studies. This approach to medication development should ultimately yield novel medications for the treatment of severe mood disorders.

\section{ACKNOWLEDGEMENTS}

Our research is supported by the Intramural Research Program of the National Institute of Mental Heath, the Stanley Foundation (HKM), the Foundation for the National Institutes of Health (Neuroscience Research Fellowship, TDG), and National Association for Research on Schizophrenia and Depression (Young Investigator Award, TDG). This review benefited from the helpful comments of Ms Alyssa M Picchini.

\section{REFERENCES}

Alimohamad H, Rajakumar N, Seah YH, Rushlow W (2005). Antipsychotics alter the protein expression levels of b-catenin and GSK-3 in the rat medial prefrontal cortex and striatum. Biolog Psychiatry 57: 533-542.

Allison JH, Stewart MA (1971). Reduced brain inositol in lithiumtreated rats. Nat N Biol 233: 267-268.

Altshuler LL, Curran JG, Hauser P, Mintz J, Denicoff K, Post R (1995). T2 hyperintensities in bipolar disorder: magnetic resonance imaging comparison and literature meta-analysis. Am J Psychiatry 152: 1139-1144.

An WL, Bjorkdahl C, Liu R, Cowburn RF, Winblad B, Pei JJ (2005). Mechanism of zinc-induced phosphorylation of p70 S6 kinase and glycogen synthase kinase 3beta in SH-SY5Y neuroblastoma cells. J Neurochem 92: 1104-1115.

Atack JR (1997). Inositol monophosphatase inhibitors - lithium mimetics? Med Res Rev 17: 215-224.

Atack JR (2000). Lithium, phosphatidylinositol signaling, and bipolar disorder. In: Manji HK, Bowden CL, Belmaker RH (eds). Bipolar Medications: Mechanism of Action. American psychiatric press Inc.: Washington, DC. pp 1-30.

Badenhop RF, Moses MJ, Scimone A, Mitchell PB, Ewen-White KR, Rosso A et al (2002). A genome screen of 13 bipolar affective disorder pedigrees provides evidence for susceptibility loci on chromosome 3 as well as chromosomes 9,13 and 19. Mol Psychiatry 7: 851-859.

Baldessarini RJ, Tondo L, Hennen J (2001). Treating the suicidal patient with bipolar disorder. Reducing suicide risk with lithium. Ann N Y Acad Sci 932: 24-38 discussion 39-43.

Bauer M, Forsthoff A, Baethge C, Adli M, Berghofer A, Dopfmer S et al (2003). Lithium augmentation therapy in refractory depression-update 2002. Eur Arch Psychiatry Clin Neurosci 253: 132-139.

Bauer MS, Mitchner L (2004). What is a 'mood stabilizer'? An evidence-based response. Am J Psychiatry 161: 3-18.

Beaulieu JM, Sotnikova TD, Yao WD, Kockeritz L, Woodgett JR, Gainetdinov RR et al (2004). Lithium antagonizes dopaminedependent behaviors mediated by an AKT/glycogen synthase kinase 3 signaling cascade. Proc Natl Acad Sci USA 101: 50995104.

Benedetti F, Bernasconi A, Lorenzi C, Pontiggia A, Serretti A, Colombo C et al (2004a). A single nucleotide polymorphism in glycogen synthase kinase 3-beta promoter gene influences onset of illness in patients affected by bipolar disorder. Neurosci Lett 355: 37-40.

Benedetti F, Serretti A, Colombo C, Lorenzi C, Tubazio V, Smeraldi E (2004b). A glycogen synthase kinase 3-beta promoter gene single nucleotide polymorphism is associated with age at onset and response to total sleep deprivation in bipolar depression. Neurosci Lett 368: 123-126.

Benedetti F, Serretti A, Pontiggia A, Bernasconi A, Lorenzi C, Colombo $C$ et al (2005). Long-term response to lithium salts in bipolar illness is influenced by the glycogen synthase kinase 3-beta-50 T/C SNP. Neurosci Lett 376: 51-55.

Bennecib M, Gong CX, Grundke-Iqbal I, Iqbal K (2000). Role of protein phosphatase-2A and -1 in the regulation of GSK-3, cdk5 and cdc2 and the phosphorylation of tau in rat forebrain. FEBS Lett 485: 87-93.

Bhat RV, Shanley J, Correll MP, Fieles WE, Keith RA, Scott CW et al (2000). Regulation and localization of tyrosine 216 phosphorylation of glycogen synthase kinase-3beta in cellular and animal models of neuronal degeneration. Proc Natl Acad Sci USA 97: 11074-11079.

Bijur GN, De Sarno P, Jope RS (2000). Glycogen synthase kinase3beta facilitates staurosporine- and heat shock-induced apoptosis. Protection by lithium. J Biol Chem 275: 7583-7590.

Bijur GN, Jope RS (2001). Proapoptotic stimuli induce nuclear accumulation of glycogen synthase kinase-3beta. J Biol Chem 8: 8 .

Blier P, Abbott FV (2001). Putative mechanisms of action of antidepressant drugs in affective and anxiety disorders and pain. J Psychiatry Neurosci 26: 37-43.

Bloch M, Daly RC, Rubinow DR (2003). Endocrine factors in the etiology of postpartum depression. Compr Psychiatry 44: 234-246.

Bondy CA, Cheng CM (2004). Signaling by insulin-like growth factor 1 in brain. Eur J Pharmacol 490: 25-31.

Bunney WE, Bunney BG (2000). Molecular clock genes in man and lower animals: possible implications for circadian abnormalities in depression. Neuropsychopharmacology 22: 335-345.

Bunney Jr WE, Davis JM (1965). Norepinephrine in depressive reactions. A review. Arch Gen Psychiatry 13: 483-494.

Cade JFj (1949). Lithium salts in the treatment of psychotic excitement. Med J Austr 2: 349-352.

Cardona-Gomez P, Perez M, Avila J, Garcia-Segura LM, Wandosell F (2004). Estradiol inhibits GSK3 and regulates interaction of estrogen receptors, GSK3, and beta-catenin in the hippocampus. Mol Cell Neurosci 25: 363-373.

Chalecka-Franaszek E, Chuang DM (1999). Lithium activates the serine/threonine kinase Akt-1 and suppresses glutamate-induced inhibition of Akt-1 activity in neurons. Proc Natl Acad Sci USA 96: 8745-8750.

Charney DS (1998). Monoamine dysfunction and the pathophysiology and treatment of depression. J Clin Psychiatry 59(Suppl 14): $11-14$

Chen G, Huang LD, Jiang YM, Manji HK (1999). The moodstabilizing agent valproate inhibits the activity of glycogen synthase kinase-3. J Neurochem 72: 1327-1330.

Chuang DM, Chen R, Chalecka-Franaszek E, Ren M, Hashimoto R, Senatorov V et al (2002). Neuroprotective effects of lithium in cultured cells and animal models of diseases. Bipolar Disord 4: 129-160.

Cohen P, Goedert M (2004). GSK3 inhibitors: development and therapeutic potential. Nat Rev Drug Discov 3: 479-487.

Cohen Y, Chetrit A, Sirota P, Modan B (1998). Cancer morbidity in psychiatric patients: influence of lithium carbonate treatment. Med Oncol 15: 32-36. 
Dajani R, Fraser E, Roe SM, Young N, Good V, Dale TC et al (2001). Crystal structure of glycogen synthase kinase 3 beta: structural basis for phosphate-primed substrate specificity and autoinhibition. Cell 105: 721-732.

De Ferrari GV, Chacon MA, Barria MI, Garrido JL, Godoy JA, Olivares $G$ et al (2003). Activation of Wnt signaling rescues neurodegeneration and behavioral impairments induced by beta-amyloid fibrils. Mol Psychiatry 8: 195-208.

De Sarno P, Li X, Jope RS (2002). Regulation of Akt and glycogen synthase kinase-3beta phosphorylation by sodium valproate and lithium. Neuropharmacology 43: 1158-1164.

Drevets WC (2000). Neuroimaging studies of mood disorders. Biol Psychiatry 48: 813-829.

Einat H, Manji HK, Belmaker RH (2003). New approaches to modeling bipolar disorder. Psychopharmacol Bull 37: 47-63.

Eldar-Finkelman H, Ilouz R (2003). Challenges and opportunities with glycogen synthase kinase-3 inhibitors for insulin resistance and type 2 diabetes treatment. Expert Opin Invest Drugs 12: 1511-1519.

Eldar-Finkelman H, Krebs EG (1997). Phosphorylation of insulin receptor substrate 1 by glycogen synthase kinase 3 impairs insulin action. Proc Natl Acad Sci USA 94: 9660-9664.

Emamian ES, Hall D, Birnbaum MJ, Karayiorgou M, Gogos JA (2004). Convergent evidence for impaired AKT1-GSK3beta signaling in schizophrenia. Nat Genet 36: 131-137.

Embi N, Rylatt DB, Cohen P (1980). Glycogen synthase kinase-3 from rabbit skeletal muscle. Separation from cyclic-AMPdependent protein kinase and phosphorylase kinase. Eur J Biochem 107: 519-527.

Evans DL, Charney DS (2003). Mood disorders and medical illness: a major public health problem. Biol Psychiatry 54: 177-180.

Fiol CJ, Mahrenholz AM, Wang Y, Roeske RW, Roach PJ (1987). Formation of protein kinase recognition sites by covalent modification of the substrate. Molecular mechanism for the synergistic action of casein kinase II and glycogen synthase kinase 3. J Biol Chem 262: 14042-14048.

Frame S, Cohen P (2001). GSK3 takes centre stage more than 20 years after its discovery. Biochem J 359: 1-16.

Frame S, Cohen P, Biondi RM (2001). A common phosphate binding site explains the unique substrate specificity of GSK3 and its inactivation by phosphorylation. Mol Cell 7: 1321-1327.

Goodwin FK, Fireman B, Simon GE, Hunkeler EM, Lee J, Revicki D (2003). Suicide risk in bipolar disorder during treatment with lithium and divalproex. JAMA 290: 1467-1473.

Gottesman II, Gould TD (2003). The endophenotype concept in psychiatry: etymology and strategic intentions. Am J Psychiatry 160: 636-645.

Gould TD, Chen G, Manji HK (2004a). In vivo evidence in the brain for lithium inhibition of glycogen synthase kinase-3. Neuropsychopharmacology 29: 32-38.

Gould TD, Einat H, Bhat R, Manji HK (2004b). AR-A014418, a selective GSK-3 inhibitor, produces antidepressant-like effects in the forced swim test. Int J Neuropsychopharmacol 4: 387-390.

Gould TD, Gray NA, Manji HK (2003). Effects of a glycogen synthase kinase- 3 inhibitor, lithium, in adenomatous polyposis coli mutant mice. Pharmacol Res 48: 49-53.

Gould TD, Quiroz JA, Singh J, Zarate CA, Manji HK (2004c). Emerging experimental therapeutics for bipolar disorder: insights from the molecular and cellular actions of current mood stabilizers. Mol Psychiatry 9: 734-755.

Grimes AC, Jope RS (2001a). CREB DNA binding activity is inhibited by glycogen synthase kinase-3beta and facilitated by lithium. J Neurochem 78: 1-15.

Grimes CA, Jope RS (2001b). The multifaceted roles of glycogen synthase kinase 3beta in cellular signaling. Prog Neurobiol 65: 391-426.

Gunin AG, Emelianov VU, Mironkin IU, Morozov MP, Tolmachev AS (2004). Lithium treatment enhances estradiol-induced proliferation and hyperplasia formation in the uterus of mice. Eur J Obstet Gynecol Reprod Biol 114: 83-91.

Gurvich N, Klein PS (2002). Lithium and valproic acid: parallels and contrasts in diverse signaling contexts. Pharmacol Ther 96: $45-66$.

Hall AC, Brennan A, Goold RG, Cleverley K, Lucas FR, GordonWeeks PR et al (2002). Valproate regulates GSK-3-mediated axonal remodeling and synapsin I clustering in developing neurons. Mol Cell Neurosci 20: 257-270.

Hansen L, Arden KC, Rasmussen SB, Viars CS, Vestergaard H, Hansen $\mathrm{T}$ et al (1997). Chromosomal mapping and mutational analysis of the coding region of the glycogen synthase kinase$3 \mathrm{alpha}$ and beta isoforms in patients with NIDDM. Diabetologia 40: $940-946$.

Healy D, Waterhouse JM (1995). The circadian system and the therapeutics of the affective disorders. Pharmacol Ther 65: 241-263.

Heninger GR, Charney DS, Sternberg DE (1983). Lithium carbonate augmentation of antidepressant treatment. An effective prescription for treatment-refractory depression. Arch Gen Psychiatry 40: 1335-1342.

Hetman M, Cavanaugh JE, Kimelman D, Xia Z (2000). Role of glycogen synthase kinase-3beta in neuronal apoptosis induced by trophic withdrawal. J Neurosci 20: 2567-2574.

Huey LY, Janowsky DS, Judd LL, Abrams A, Parker D, Clopton P (1981). Effects of lithium carbonate on methylphenidate-induced mood, behavior, and cognitive processes. Psychopharmacology (Berl) 73: 161-164.

Ilouz R, Kaidanovich O, Gurwitz D, Eldar-Finkelman H (2002). Inhibition of glycogen synthase kinase-3beta by bivalent zinc ions: insight into the insulin-mimetic action of zinc. Biochem Biophys Res Commun 295: 102-106.

Iwahana E, Akiyama M, Miyakawa K, Uchida A, Kasahara J, Fukunaga $\mathrm{K}$ et al (2004). Effect of lithium on the circadian rhythms of locomotor activity and glycogen synthase kinase-3 protein expression in the mouse suprachiasmatic nuclei. Eur $J$ Neurosci 19: 2281-2287.

Jope RS, Bijur GN (2002). Mood stabilizers, glycogen synthase kinase-3beta and cell survival. Mol Psychiatry 7(Suppl 1): S35-S45.

Jope RS, Johnson GV (2004). The glamour and gloom of glycogen synthase kinase-3. Trends Biochem Sci 29: 95-102.

Kaidanovich-Beilin O, Milman A, Weizman A, Pick CG, EldarFinkelman H (2004). Rapid antidepressive-like activity of specific glycogen synthase kinase-3 inhibitor and its effect on beta-catenin in mouse hippocampus. Biol Psychiatry 55: 781-784.

Kang UG, Roh MS, Jung JR, Shin SY, Lee YH, Park JB, Kim YS (2004a). Activation of protein kinase B (Akt) signaling after electroconvulsive shock in the rat hippocampus. Prog Neuropsychopharmacol Biol Psychiatry 28: 41-44.

Kang UG, Seo MS, Roh MS, Kim Y, Yoon SC, Kim YS (2004b). The effects of clozapine on the GSK-3-mediated signaling pathway. FEBS Lett 560: 115-119.

Kim AJ, Shi Y, Austin RC, Werstuck GH (2005). Valproate protects cells from ER stress-induced lipid accumulation and apoptosis by inhibiting glycogen synthase kinase-3. J Cell Sci 118: 89-99.

Kirshenboim N, Plotkin B, Shlomo SB, Kaidanovich-Beilin O, Eldar-Finkelman H (2004). Lithium-mediated phosphorylation of glycogen synthase kinase-3b involves PI3 kinase-dependent activation of protein kinase C-alpha. J Mol Neurosci 24: 237-246.

Klein PS, Melton DA (1996). A molecular mechanism for the effect of lithium on development. Proc Natl Acad Sci USA 93: $8455-8459$.

Klemfuss H (1992). Rhythms and the pharmacology of lithium. Pharmacol Ther 56: 53-78.

Kouzmenko AP, Takeyama K, Ito S, Furutani T, Sawatsubashi S, Maki A et al (2004). Wnt/beta-catenin and estrogen signaling converge in vivo. J Biol Chem 279: 40255-40258. 
Kroczka B, Branski P, Palucha A, Pilc A, Nowak G (2001). Antidepressant-like properties of zinc in rodent forced swim test. Brain Res Bull 55: 297-300.

Kroczka B, Zieba A, Dudek D, Pilc A, Nowak G (2000). Zinc exhibits an antidepressant-like effect in the forced swimming test in mice. Pol J Pharmacol 52: 403-406.

Lamberty Y, Margineanu DG, Klitgaard H (2001). Effect of the new antiepileptic drug levetiracetam in an animal model of mania. Epilepsy Behav 2: 454-459.

Lee SJ, McEwen BS (2001). Neurotrophic and neuroprotective actions of estrogens and their therapeutic implications. Annu Rev Pharmacol Toxicol 41: 569-591.

Lenox RH, Gould TD, Manji HK (2002). Endophenotypes in bipolar disorder. Am J Med Genet 114: 391-406.

Li X, Bijur GN, Jope RS (2002). Glycogen synthase kinase 3-beta, mood stabilizers, and neuroprotection. Bipolar Disord 4: 137-144.

Li X, Zhu W, Roh MS, Friedman AB, Rosborough K, Jope RS (2004). In vivo regulation of glycogen synthase kinase-3beta (GSK3beta) by serotonergic activity in mouse brain. Neuropsychopharmacology 29: 1426-1431.

Linseman DA, Butts BD, Precht TA, Phelps RA, Le SS, Laessig TA et al (2004). Glycogen synthase kinase-3beta phosphorylates Bax and promotes its mitochondrial localization during neuronal apoptosis. J Neurosci 24: 9993-10002.

Logan CY, Nusse R (2004). The Wnt signaling pathway in development and disease. Annu Rev Cell Dev Biol 20: 781-810.

Lopez JF, Neale CR, Meader-Woodruff JH (2004). Methods of postmortem investigation of the human brain. In Charney DS, Nester EJ (eds). Neurobiology of Mental Illness. Oxford University Press: New York. pp 210-220.

Madsen TM, Newton SS, Eaton ME, Russell DS, Duman RS (2003). Chronic electroconvulsive seizure up-regulates beta-catenin expression in rat hippocampus: role in adult neurogenesis. Biol Psychiatry 54: 1006-1014.

Maggirwar SB, Tong N, Ramirez S, Gelbard HA, Dewhurst S (1999). HIV-1 Tat-mediated activation of glycogen synthase kinase-3beta contributes to Tat-mediated neurotoxicity. $J$ Neurochem 73: 578-586.

Malberg JE, Eisch AJ, Nestler EJ, Duman RS (2000). Chronic antidepressant treatment increases neurogenesis in adult rat hippocampus. J Neurosci 20: 9104-9110.

Manji HK, Drevets WC, Charney DS (2001). The cellular neurobiology of depression. Nat Med 7: 541-547.

Manji HK, Moore GJ, Chen G (1999). Lithium at 50: have the neuroprotective effects of this unique cation been overlooked? Biol Psychiatry 46: 929-940.

Manji HK, Moore GJ, Rajkowska G, Chen G (2000). Neuroplasticity and cellular resilience in mood disorders. Mol Psychiatry 5: 578-593.

Martinek S, Inonog S, Manoukian AS, Young MW (2001). A role for the segment polarity gene shaggy/GSK-3 in the Drosophila circadian clock. Cell 105: 769-779.

Moore GJ, Bebchuk JM, Hasanat K, Chen G, Seraji-Bozorgzad N, Wilds IB et al (2000a). Lithium increases $N$-acetyl-aspartate in the human brain: in vivo evidence in support of bcl-2's neurotrophic effects? Biol Psychiatry 48: 1-8.

Moore GJ, Bebchuk JM, Parrish JK, Faulk MW, Arfken CL, StrahlBevacqua J et al (1999). Temporal dissociation between lithiuminduced changes in frontal lobe myo-inositol and clinical response in manic-depressive illness. Am J Psychiatry 156: $1902-1908$.

Moore GJ, Bebchuk JM, Wilds IB, Chen G, Manji HK, Menji HK (2000b). Lithium-induced increase in human brain grey matter. Lancet 356: 1241-1242.

Mukherjee S, Sackeim HA, Schnur DB (1994). Electroconvulsive therapy of acute manic episodes: a review of 50 years' experience. Am J Psychiatry 151: 169-176.
Muller-Oerlinghausen B (2001). Arguments for the specificity of the antisuicidal effect of lithium. Eur Arch Psychiatry Clin Neurosci 251(Suppl 2): II72-5.

Munoz-Montano JR, Moreno FJ, Avila J, Diaz-Nido J (1997). Lithium inhibits Alzheimer's disease-like tau protein phosphorylation in neurons. FEBS Lett 411: 183-188.

Nowak G, Siwek M, Dudek D, Zieba A, Pilc A (2003a). Effect of zinc supplementation on antidepressant therapy in unipolar depression: a preliminary placebo-controlled study. Pol J Pharmacol 55: $1143-1147$.

Nowak G, Szewczyk B, Wieronska JM, Branski P, Palucha A, Pilc A et al (2003b). Antidepressant-like effects of acute and chronic treatment with zinc in forced swim test and olfactory bulbectomy model in rats. Brain Res Bull 61: 159-164.

O’Brien WT, Harper AD, Jove F, Woodgett JR, Maretto S, Piccolo S et al (2004). Glycogen synthase kinase-3beta haploinsufficiency mimics the behavioral and molecular effects of lithium. $J$ Neurosci 24: 6791-6798.

Ohnaka K, Tanabe M, Kawate H, Nawata H, Takayanagi R (2005). Glucocorticoid suppresses the canonical Wnt signal in cultured human osteoblasts. Biochem Biophys Res Commun 329: 177-181.

Padiath QS, Paranjpe D, Jain S, Sharma VK (2004). Glycogen synthase kinase 3beta as a likely target for the action of lithium on circadian clocks. Chronobiol Int 21: 43-55.

Pap M, Cooper GM (1998). Role of glycogen synthase kinase-3 in the phosphatidylinositol 3-kinase/Akt cell survival pathway. J Biol Chem 273: 19929-19932.

Payne JL (2003). The role of estrogen in mood disorders in women. Int Rev Psychiatry 15: 280-290.

Perez M, Hernandez F, Lim F, Diaz-Nido J, Avila J (2003). Chronic lithium treatment decreases mutant tau protein aggregation in a transgenic mouse model. J Alzheimers Dis 5: 301-308.

Phiel CJ, Wilson CA, Lee VM, Klein PS (2003). GSK-3alpha regulates production of Alzheimer's disease amyloid-beta peptides. Nature 423: 435-439.

Phiel CJ, Zhang F, Huang EY, Guenther MG, Lazar MA, Klein PS (2001). Histone deacetylase is a direct target of valproic acid, a potent anticonvulsant, mood stabilizer, and teratogen. J Biol Chem 276: 36734-36741.

Plenge P (1976). Acute lithium effects on rat brain glucose metabolism - in vivo. Int Pharmacopsychiatry 11: 84-92.

Plotkin B, Kaidanovich O, Talior I, Eldar-Finkelman H (2003). Insulin mimetic action of synthetic phosphorylated peptide inhibitors of glycogen synthase kinase-3. J Pharmacol Exp Ther 305: 974-980.

Porsolt RD, Le Pichon M, Jalfre M (1977). Depression: a new animal model sensitive to antidepressant treatments. Nature 266: 730-732.

Quiroz JA, Singh J, Gould TD, Denicoff KD, Zarate CA, Manji HK (2004). Emerging experimental therapeutics for bipolar disorder: clues from the molecular pathophysiology. Mol Psychiatry 9: 756-776.

Rajkowska G (2002). Cell pathology in bipolar disorder. Bipolar Disord 4: 116-129.

Ramirez VD, Kipp JL, Joe I (2001). Estradiol, in the CNS, targets several physiologically relevant membrane-associated proteins. Brain Res Brain Res Rev 37: 141-152.

Reppert SM, Weaver DR (2000). Comparing clockworks: mouse versus fly. J Biol Rhythms 15: 357-364.

Roh MS, Eom TY, Zmijewska AA, De Sarno P, Roth KA, Jope RS (2005). Hypoxia activates glycogen synthase kinase-3 in mouse brain in vivo: protection by mood stabilizers and imipramine. Biol Psychiatry 57: 278-286.

Roh MS, Kang UG, Shin SY, Lee YH, Jung HY, Juhnn YS et al (2003). Biphasic changes in the Ser-9 phosphorylation of glycogen synthase kinase-3beta after electroconvulsive shock in the rat brain. Prog Neuropsychopharmacol Biol Psychiatry 27: $1-5$. 
Ryves WJ, Dajani R, Pearl L, Harwood AJ (2002). Glycogen synthase kinase- 3 inhibition by lithium and beryllium suggests the presence of two magnesium binding sites. Biochem Biophys Res Commun 290: 967-972.

Ryves WJ, Harwood AJ (2001). Lithium inhibits glycogen synthase kinase-3 by competition for magnesium. Biochem Biophys Res Commun 280: 720-725.

Sapolsky RM (1996). Stress, glucocorticoids, and damage to the nervous system: the current state of confusion. Stress 1: 1-19.

Schildkraut JJ (1965). The catecholamine hypothesis of affective disorders: a review of supporting evidence. Am J Psychiatry 122: 509-522.

Schou M (2001). Lithium treatment at 52. J Affect Disord 67: 21-32.

Seibyl JP, Scanley BE, Krystal JH, Innis RB (2004). Neuroimaging methodologies: utilizing radiotracers or nuclear magnetic resonance. In Charney DS, Nester EJ (eds). Neurobiology of Mental Illness. Oxford University Press: New York. pp 190-209.

Shaw PC, Davies AF, Lau KF, Garcia-Barcelo M, Waye MM, Lovestone S, Miller CC, Anderton BH (1998). Isolation and chromosomal mapping of human glycogen synthase kinase-3 alpha and -3 beta encoding genes. Genome 41: 720-727.

Smith E, Frenkel B (2004). Glucocorticoids inhibit LEF/TCF transcriptional activity in differentiating osteoblasts in a GSK3\{beta\}-dependent and independent manner. J Biol Chem 280: 2388-2394.

Souza FG, Goodwin GM (1991). Lithium treatment and prophylaxis in unipolar depression: a meta-analysis. Br J Psychiatry 158: 666-675.

Stambolic V, Ruel L, Woodgett JR (1996). Lithium inhibits glycogen synthase kinase-3 activity and mimics wingless signalling in intact cells. Curr Biol 6: 1664-1668.

Su Y, Ryder J, Li B, Wu X, Fox N, Solenberg P et al (2004). Lithium, a common drug for bipolar disorder treatment, regulates amyloid-beta precursor protein processing. Biochemistry 43: 6899-6908.

Svenningsson P, Tzavara ET, Carruthers R, Rachleff I, Wattler S, Nehls $M$ et al (2003). Diverse psychotomimetics act through a common signaling pathway. Science 302: 1412-1415.

Szewczyk B, Branski P, Wieronska JM, Palucha A, Pilc A, Nowak G (2002). Interaction of zinc with antidepressants in the forced swimming test in mice. Pol J Pharmacol 54: 681-685.

Takashima A, Noguchi K, Sato K, Hoshino T, Imahori K (1993). Tau protein kinase I is essential for amyloid beta-proteininduced neurotoxicity. Proc Natl Acad Sci USA 90: 7789-7793.

Tanji C, Yamamoto H, Yorioka N, Kohno N, Kikuchi K, Kikuchi A (2002). A-kinase anchoring protein AKAP220 binds to glycogen synthase kinase-3beta (GSK-3beta) and mediates protein kinase
A-dependent inhibition of GSK-3beta. J Biol Chem 277: 3695536961.

Tubazio V, Benedetti F, Serretti A, Plioa C, Pirovano A, Smeraldi E (2004). Glycogen synthase kinase (GSK) gene promoter polymorphism: a TDT and haplotype approach in mood disorders. Am J Med Genet 130B: P1.24.

van Kammen DP, Docherty JP, Marder SR, Rosenblatt JE, Bunney Jr WE (1985). Lithium attenuates the activation-euphoria but not the psychosis induced by $d$-amphetamine in schizophrenia. Psychopharmacology (Berl) 87: 111-115.

Van Kammen DP, Murphy DL (1975). Attenuation of the euphoriant and activating effects of $d$ - and $l$-amphetamine by lithium carbonate treatment. Psychopharmacologia 44: 215-224.

Walsh BT, Seidman SN, Sysko R, Gould M (2002). Placebo response in studies of major depression: variable, substantial, and growing. Jama 287: 1840-1847.

Watcharasit P, Bijur GN, Zmijewski JW, Song L, Zmijewska A, Chen X et al (2002). Direct, activating interaction between glycogen synthase kinase-3beta and p53 after DNA damage. Proc Natl Acad Sci USA 99: 7951-7955.

Wehr TA, Wirz-Justice A (1982). Circadian rhythm mechanisms in affective illness and in antidepressant drug action. Pharmacopsychiatria 15: 31-39.

Welsh GI, Proud CG (1993). Glycogen synthase kinase-3 is rapidly inactivated in response to insulin and phosphorylates eukaryotic initiation factor eIF-2B. Biochem J 294(Part 3): 625-629.

Werstuck GH, Kim AJ, Brenstrum T, Ohnmacht SA, Panna E, Capretta A (2004). Examining the correlations between GSK-3 inhibitory properties and anti-convulsant efficacy of valproate and valproate-related compounds. Bioorg Med Chem Lett 14: 5465-5467.

Williams RS, Cheng L, Mudge AW, Harwood AJ (2002). A common mechanism of action for three mood-stabilizing drugs. Nature 417: 292-295.

Williams RS, Eickholt BJ, Towers G, Ryves WJ, Eikel D, Adley K et al (2005). Effects of valproic acid derivatives on inositol trisphosphate depletion, teratogenicity, GSK-3 \{beta\} inhibition and viral replication - a screening approach for new bipolar disorder drugs based on the valproic acid core structure. Mol Pharmacol [Epub ahead of print].

Wyska E, Szymura-Oleksiak J, Opoka W, Bas B, Niewiara E, Pomierny L et al (2004). Pharmacokinetic interaction after joint administration of zinc and imipramine in forced swim test in mice. Pol J Pharmacol 56: 479-484.

Zhang F, Phiel CJ, Spece L, Gurvich N, Klein PS (2003). Inhibitory phosphorylation of glycogen synthase kinase-3 (GSK-3) in response to lithium. Evidence for autoregulation of GSK-3. J Biol Chem 278: 33067-33077. 